\title{
Effect of Vitamin D deficiency on Lipid Profile
}

\author{
Nabil Ahmad Bashir ${ }^{1, ~ *, ~ A d n a n ~ A h m a d ~ M o h a m m a d ~ B a s h i r ², ~ H a n i ~ A d n a n ~ B a s h i r ~}{ }^{3}$ \\ ${ }^{1}$ Department of Physiology and Biochemistry and Department of Medical Laboratory Sciences, Faculty of Medicine, Balqa Applied \\ University Medical School (Sabbatical) and Jordan University of Science and Technology, Irbid, Jordan \\ ${ }^{2}$ Industrial Engineering Department, Abu Dhabi University and Hashemite University, Zarqa, Jordan \\ ${ }^{3}$ School of Medicine, Hashemite University, Zarqa, Jordan
}

Email address:

nbashir@just.edu.jo (N. A. Bashir)

${ }^{*}$ Corresponding author

\section{To cite this article:}

Nabil Ahmad Bashir, Adnan Ahmad Mohammad Bashir, Hani Adnan Bashir. Effect of Vitamin D deficiency on Lipid Profile. American Journal of Laboratory Medicine. Vol. 4, No. 1, 2019, pp. 11-18. doi: 10.11648/j.ajlm.20190401.12

Received: December 12, 2018; Accepted: December 27, 2018; Published: March 25, 2019

\begin{abstract}
The purpose of this study is to investigate the effect of vitamin D deficiency on lipid parameters; cholesterol, triglycerides, low density lipoprotein (LDL), and high density lipoprotein (HDL). Serum level of vitamin D and the lipid parameters were determined in 127 subjects attending private community lab in eastern Amman province, using commercially available kits. Deficiency and insufficiency of vitamin D were 36.2\%, 29.9\%, respectively. Serum level of cholesterol, triglycerides, and LDL in deficient and insufficient vitamin D subjects were significantly increased, while HDL level was decreased, P-value $<0.05$. Serum levels of lipid profile and vitamin D in each of the control, insufficient, and deficient groups were all normally distributed due to the fact that P-value is greater than 0.05. Interval plot analysis and One-way ANOVA analysis revealed a significant effect of vitamin D insufficiency or deficiency on serum level of cholesterol, triglycerides, and LDL and increases the levels more than the double. Two samples T-test for every lipid parameter analysis related to subjects in the sufficient, insufficient and deficient vitamin D groups confirm our hypothesis on the effect of vitamin D deficiency on increasing the levels of cholesterol, triglycerides, and LDL and decreasing the level of HDL.
\end{abstract}

Keywords: Vitamin D, Cholesterol, Triglycerides, Low Density Lipoprotein, High Density Lipoprotein

\section{Introduction}

Dyslipidemia is characterized by hypertriglyceridemia, hypercholesterolemia, reduced high density lipoprotein, and elevated low density lipoprotein. Dyslipidemia is considered as a key factor associated with the increased risks of several cardiovascular disease [1], which is considered as a major causative factor for death [2]. The therapeutic interventions for lowering level of cholesterol can also decrease the mortality and morbidity due to cardiovascular diseases. Some research studies have also demonstrated a link between dyslipidemia and decreased concentration of vitamin D [3]. Vitamin D is one of essential fat soluble vitamin, which performs many functions in the human body. The prime source providing vitamin D to human is exposure to sunlight [4]. The skin contain 7-dehydrocholesterol which after absorption of the ultraviolet $\mathrm{B}$ radiation is converted to previtamin D3 and after that it is hydroxylated into $25(\mathrm{OH}) \mathrm{D}$ and then converted into 1,25-dihydroxyvitamin D3 with the help of hydroxylases found in kidneys and livers. The sources of vitamin D are oral supplements and diet. Bone metabolism and regulation of calcium are important physiological functions of vitamin D [5]. In addition, vitamin $\mathrm{D}$ is also considered as a modulator of immune system functions, anti-inflammatory activity, reduce resistance of insulin, and suppress rennin-angiotensin system. In addition, it is stated by several research studies that deficiency of vitamin $\mathrm{D}$ is significantly associated with some cardiovascular diseases. The predefined aim of this research study is to determine the effect of vitamin D deficiency or insufficiency on serum levels of cholesterol, triglcerides, LDL, and HDL. The specific objectives of this research study is to demonstrate the effect of low levels of vitamin D on lipid profile. 


\section{Literature Review}

The importance of vitamin D is described by several research studies and some of researcher have also focused on determining vitamin $\mathrm{D}$ impact on the lipid profile of a person. It is suggested by some researchers that concentration of vitamin D has a strong association with the dyslipidemia and risks of different cardiovascular disorders [1-7]. As stated in the literature, deficiency in vitamin $\mathrm{D}$ is significantly associated with prevalence of some cardiovascular disease as well as dyslipidemia. It has been demonstrated by other researchers that the decreased level of $25(\mathrm{OH}) \mathrm{D}$ is associated independent with increased mortality rates of the patients having cardiovascular disease [8]. Some other research studies have also presented the association with deficiency of vitamin D and dyslipidemia and several cardiovascular diseases $[9,10]$. Other research studies have also presented a significant association between dyslipidemia and decreased level of vitamin, yet outcomes of most of these research studies were insignificant [8-10]. Some other researchers have highlighted the significance of increasing blood level of vitamin $\mathrm{D}$ to reduce the risks of different dyslipidemia associated cardiovascular diseases such as stroke, myocardial infarction, and hypertension [9, 11]. The abnormalities of lipoproteins can be associated with increased levels of LDL$\mathrm{C}$, TG, TC, or reduced levels of HDL-C and in case of vitamin $\mathrm{D}$ deficiency, risks of these abnormalities are increased to a high level. The increased level of these lipoproteins has a significant association with the cardiovascular morbidity. Yet, there is limited research demonstrating the association of vitamin D deficiency and lipid profile induced cardiovascular diseases [11]. However, some researchers have provided the association between the level of lipids in serum and levels of $25(\mathrm{OH}) \mathrm{D}$. The outcomes of a cross-sectional study that was carried out to determine the relationship between the levels of vitamin D and lipoproteins have revealed positive outcomes [12]. A research study had presented that the levels of serum $25(\mathrm{OH}) \mathrm{D}$ have a positive relationship with the levels of LDL-C, TC, and HDL-C, and negative association between the levels of 25(OH)D and serum levels of TG. However, the outcomes obtained from another study were completely different and suggested a negative association between levels of TG, TC, and LDL-C, while the relationship between HDL$\mathrm{C}$ and $25(\mathrm{OH}) \mathrm{D}$ was found positive and significant [13].

\section{Subjects and Methods}

\subsection{Subject}

Serum level of Vitamin D and lipid profile were assesed in blood samples taken from 127 subjects attending the lab for routine blood testing. Criteria for dyslipidemia patients weather they are taking lipid lowering medications or not, and if the patient had type 2 diabetes, the above criteria and the presence of LDL-c levels $>65 \mathrm{mg} / \mathrm{dl}$ are mandatory. None of the subjects are taking vitamin D supplements. Informed consent was obtained from all individual participants included in the study. According to serum level of vitamin D, these subjects were categorized into three groups; forty three sufficient vitamin D subjects ( $>30 \mathrm{ng} / \mathrm{ml})$, (Control group 1), thirty eight insufficient (15-30ng/ml) (group 2), and forty six deficient $(<15 \mathrm{ng} / \mathrm{ml})$ (group 3).

\subsection{Biochemical Analysis}

Blood specimens were obtained after overnight fasting in plain tubes, and have been frozen at $-20^{\circ} \mathrm{C}$ till annalysis. The lipid profile included total cholesterol, triglycerides, and HDL-c which were measured by commercially available kits for all participants. LDLc was calculated using Friedewald's equation when triglycerides did not exceed $300 \mathrm{mg} / \mathrm{dl}$. Vitamin D was determined by radioimmunoflourescence commercially available kits (TOSOH ST AIA-PACK).

\subsection{Statistical Analysis}

Data were analyzed using the MiniTab software. Normality of data distribution was evaluated using Kolmogorov-Smirnov in the transversal analysis. The relationship between qualitative variables was assessed using Chi-square test and quantitative variables were analyzed by means of Pearson's or Spearman's correlation coefficient. Differences between groups were evaluated by T-test, MannWhitney test and Interval Plot Analysis. The level of statistical significance Alpha $(\alpha)=0.05$.

\section{Results}

\subsection{Lipid Profile and Vitamin D Status in Deficient and Insufficient Groups}

As shown in Table 1, the frequency of vitamin D sufficient group (control), insufficient vitamin D group, and deficient group was $43(33.9 \%), 38(29.9 \%)$, and $46(36.2 \%)$, respectively. In the insufficient vitamin $\mathrm{D}$ group, the concentration of vitamin D $(\mathrm{ng} / \mathrm{ml})$, glucose $(\mathrm{mg} / \mathrm{dl})$, cholesterol $(\mathrm{mg} / \mathrm{dl})$, triglycerides $(\mathrm{mg} / \mathrm{dl})$, HDL $(\mathrm{mg} / \mathrm{dl})$, and LDL $(\mathrm{mg} / \mathrm{dl})$ are $18.8 \pm 2.44, \quad 213.8 \pm 99.6, \quad 244.3 \pm 40.88$, $265.6 \pm 128.4,46.17 \pm 13.73$, and $145.02 \pm 40.6$, while in the deficient group the concentrations are; 11.26 \pm 1.8 , $215.2 \pm 80.1, \quad 239.7 \pm 65.51, \quad 246 \pm 148.6, \quad 48.6 \pm 18.66$, and $142.81 \pm 47.69$, respectively. (Table 2, Figure 1). The difference in mean of glucose, cholesterol, triglycerides, LDL, and HDL between contols and each of insufficent and deficient groups is significant, $\mathrm{P}<0.05$ as presented in Table 2 and figure 1 . There is no significant difference in serum levels of vitamin $\mathrm{D}$, glucose, total cholesterol, triglycerides, HDL, or LDL, between the insufficient vitamin D and deficient groups, $\mathrm{P}>0.05$. 
Table 1. Status of vitamin D in a random selected sample of 127 participants in eastren Amman province, Jordan.

\begin{tabular}{lll}
\hline Groups of vitamin D & Number, n & Percentage, \% \\
\hline Group 1: Sufficient vitamin D $(>30 \mathrm{ng} / \mathrm{ml})$ & 43 & 33.9 \\
Group 2: Insufficient $(15-30 \mathrm{ng} / \mathrm{ml})$ & 38 & 29.9 \\
Goup 3: Deficient $(<15 \mathrm{ng} / \mathrm{ml})$ & 46 & 36.2 \\
\hline
\end{tabular}

Table 2. Serum levels of vitamin D, glucose, and lipid profile in Group I: (Sufficient Vitamin D, $n=43$ ), Group II (Insufficient Vitamin D , $n=38)$, and Group III ( Deficiency Vitamin D, $n=46$ ).

\begin{tabular}{llllll}
\hline \multirow{2}{*}{ Tested parameters } & \multicolumn{2}{c}{ Group I: Sufficient Vitamin D (n=43) } & \multicolumn{2}{c}{$\begin{array}{l}\text { Group II: Insufficient } \\
\text { Vitamin D (n=38) }\end{array}$} & $\begin{array}{l}\text { Group III: Deficiency } \\
\text { Vitamin D (n=46) }\end{array}$ \\
\cline { 2 - 6 } & Mean & Stand. Dev. & Mean & Stand. Dev. & Mean \\
\hline Vitamin D (ng/ml) & 42.14 & 9.47 & 18.8 & 2.44 & 11.26 \\
Glucose (mg/dl) & 92.23 & 9.43 & 213.8 & 99.6 & 215.2 \\
Cholesterol (mg/dl) & 148.1 & 15.25 & 244.3 & 40.88 & 239.7 \\
Triglyceride (mg/dl) & 143.5 & 25.17 & 265.6 & 128.4 & 246 \\
HDL (mg/dl) & 63.33 & 12.84 & 46.17 & 13.73 & 40.1 \\
LDL (mg/dl) & 56.02 & 10.19 & 145.02 & 40.6 & 48.6 \\
\hline
\end{tabular}

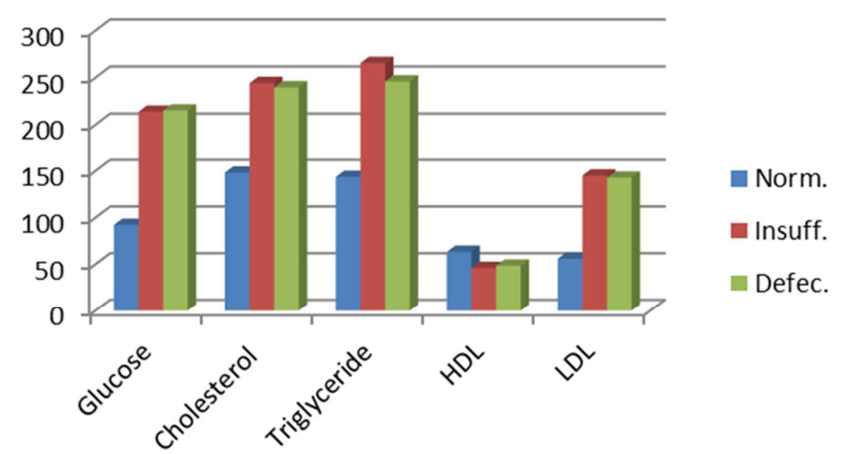

Figure 1. Serum levels of glucose and lipids panel in suffient control group, $n=43$ (Norm), insufficient vitamin D group, $n=38$ (Insuff.), and vitamin D deficient group, $n=46$ (Defec.).

\subsection{Normality Testing}

Group 1 (sufficient vitamin D with normal lipid profile) data, group 2 (insufficient vitamin $\mathrm{D}$ with abnormal lipid profile), and group 3 (deficient vitamin D with abnormal lipid profile) all follow normal distribution, P-vale $>0.05$. (Figures 2, 3, and 4)

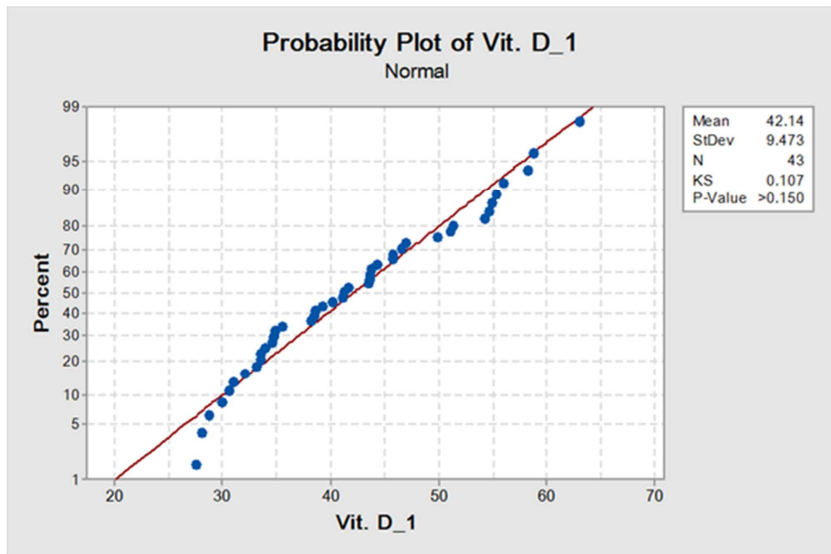

Figure 2. Distribution of serum levels of vitamin D in group I - normal lipids, normal vitamin $D$ in 43 subjects, mean=42.14 $\mathrm{ng} / \mathrm{ml}$, standard deviation $=9.47, P$ value $>0.15$.

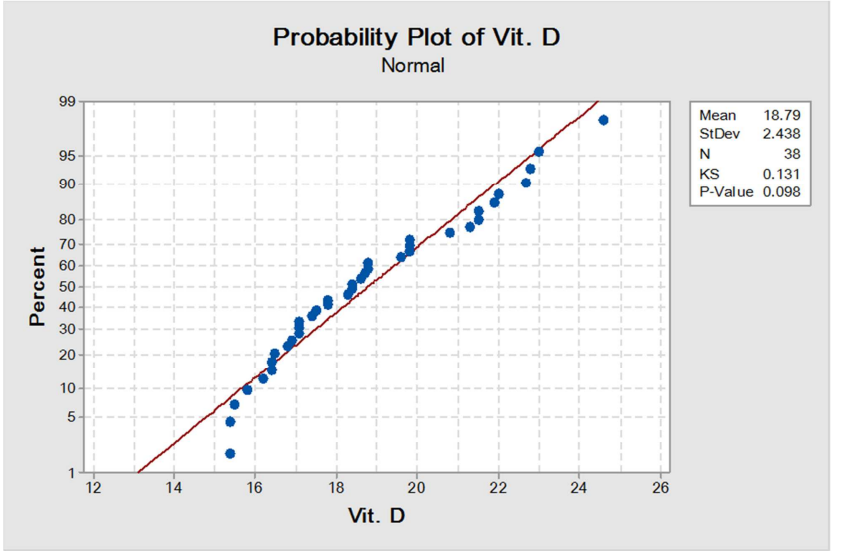

Figure 3. Distribution of serum levels of vitamin D in group II (insufficient vitamin D) in 38 subjects, mean $=18.79 \mathrm{ng} / \mathrm{ml}$, standard deviation $=2.44, P$ value $>0.098$.

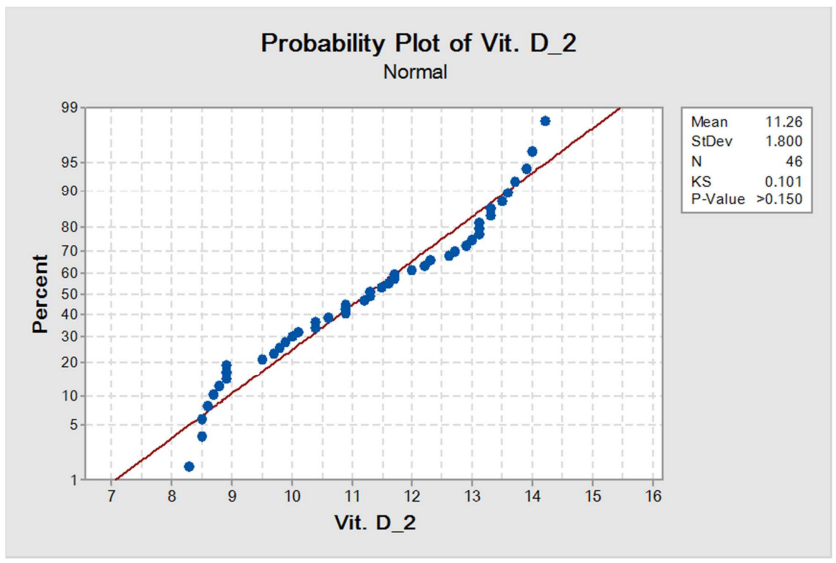

Figure 4. Distribution of serum levels of vitamin D in group III (deficient vitamin D) in 46 subjects, mean $=11.26 \mathrm{ng} / \mathrm{ml}$, standard deviation $=1.8, P$ value $>0.15$.

\subsection{Comparison Between Lipid Parameters for Different Groups of Vitamin D and Analysis of Variances}

The effect of vitamin D deficiency or insufficiency on on the mean of different variables (glucose, TC, TG, LDL, and HDL) was evaluated by using interval plot annalysis and one 
way ANOVA . Elevated levels of glucose, total cholesterol, triglycerides, and LDL, and low level of serum HDL were observed. Glucose levels in vitamin D deficient group, normal vitamin D group, and in vitamin D insufficient group was $221.7 \pm 105.6,95 \%$ CI $(197.9 ; 245.5), 92.23 \pm 9.43,95 \%$ CI $(69.30 ; 115.17) 215.2 \pm 80.1,95 \%$ CI $(193.1 ; 237.4)$, respectively. (figure 5).

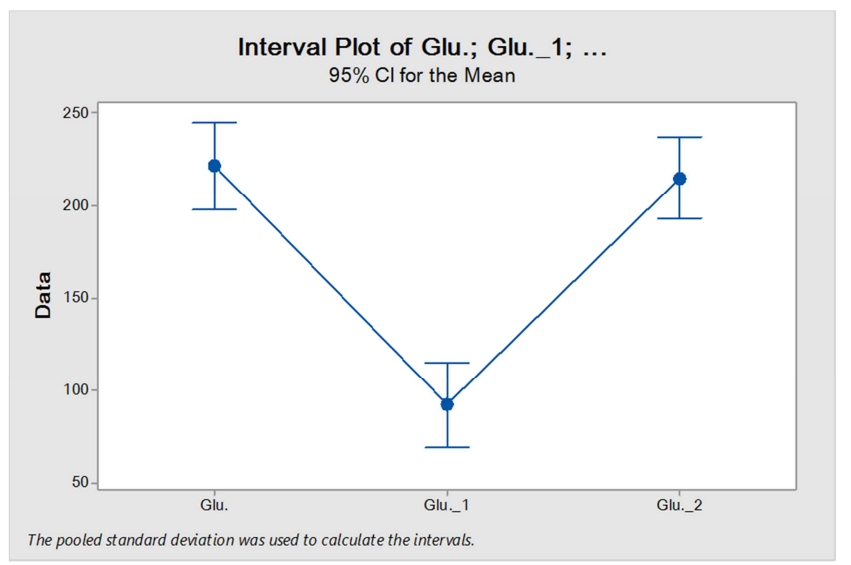

Figure 5. Interval plot analysis to compare between glucose levels for different groups of Vitamin D, Glu_l (group I; sufficient control group, $n=43$ ), Glu_2 (group II; insufficient vitamin D group, $n=38$ ), Glu (group III; deficient vitamin D group, $n=46$ ).

Total cholesterol levels in vitamin D deficient group, normal vitamin D group, and in vitamin D insufficient group was $262.2 \pm 68.8,95 \%$ CI ( $244.8 ; 279.5), 148.05 \pm 15.27$, $95 \%$ CI $(131.31 ; 164.78), 239.65 \pm 65.51,95 \%$ CI $(223.47$; 255.83), respectively.(figure 6).

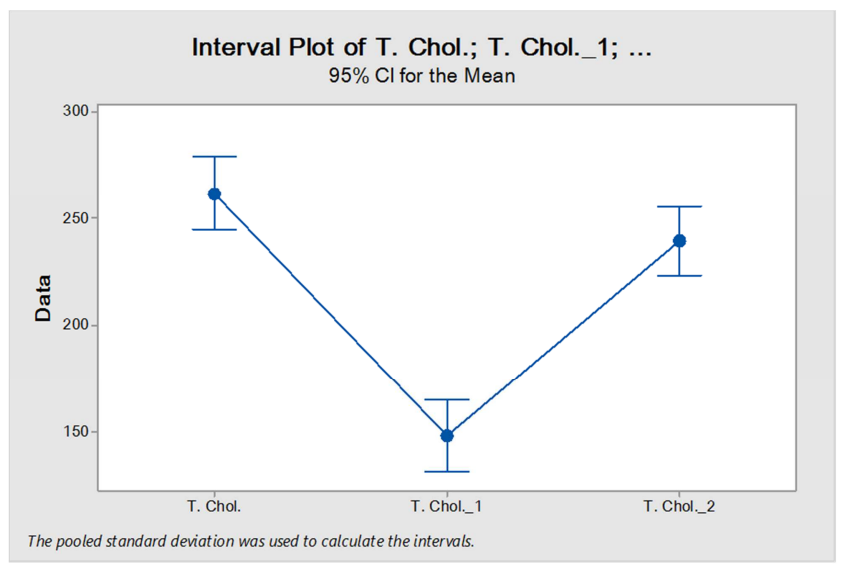

Figure 6. Interval plot analysis to compare between total cholesterol levels for different groups of Vitamin D, T. Chol_1 (group I; sufficient control group, $n=43$ ), T. Chol_2 (group II; insufficient vitamin D group, $n=38$ ), $T$. Chol. (group III; deficient vitamin D group, $n=46$ ).

Triglycerides levels in vitamin D deficient group, normal vitamin D group, and in vitamin D insufficient group was $276.1 \pm 136.9,95 \%$ CI $(239.2 ; 313.0), 143.49 \pm 25.17,95 \%$ CI $(107.92 ; 179.06)$, and $246.0 \pm 148.6,95 \%$ CI ( 211.6 ; 280.3), respectively, Figure 7.

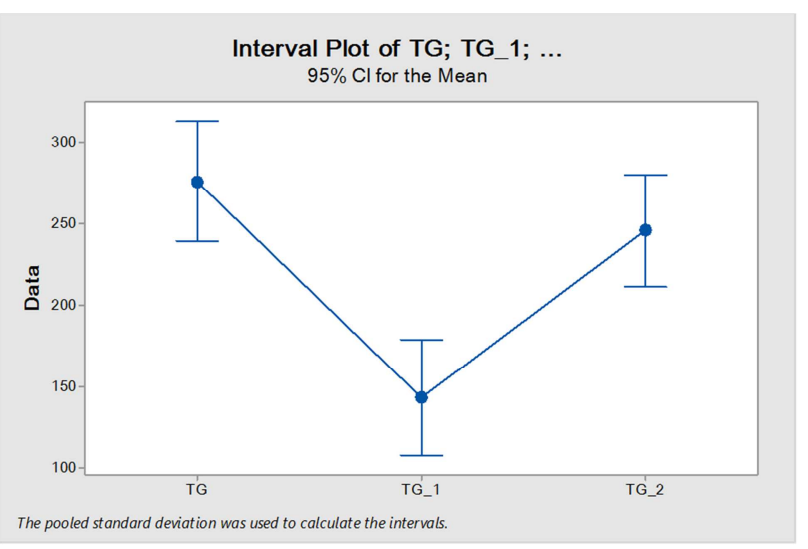

Figure 7. Interval plot analysis to compare between triglycerides levels for different groups of Vitamin D, TG_l (group I; sufficient control group, $n=43$ ), TG_2 (group II; insufficient vitamin D group, $n=38$ ), TG (group III; deficient vitamin D group, $n=46$ ).

High density lipoprotein (HDL) levels in vitamin D deficient group, normal vitamin $\mathrm{D}$ group, and in vitamin $\mathrm{D}$ insufficient group was $47.13 \pm 15.00,95 \%$ CI $(42.20 ; 52.07)$, $63.33 \pm 12.84,95 \% \mathrm{CI}(58.57 ; 68.09)$, and $48.60 \pm 18.66$, $95 \%$ CI $(44.00 ; 53.21)$, respectively, Figure 8.

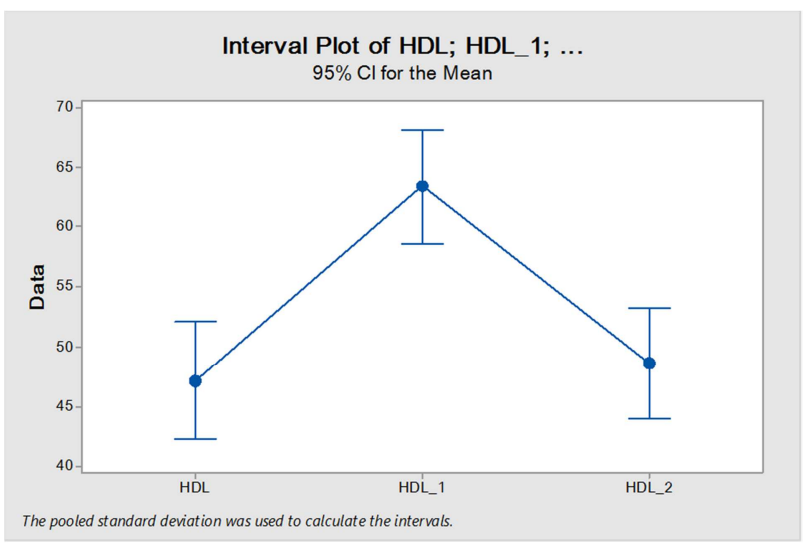

Figure 8. Interval plot analysis to compare between HDL levels for different groups of Vitamin D, HDL_1 (group I; sufficient control group, $n=43$ ), HDL_2 (group II; insufficient vitamin D group, $n=38$ ), HDL (group III; deficient vitamin D group, $n=46$ ).

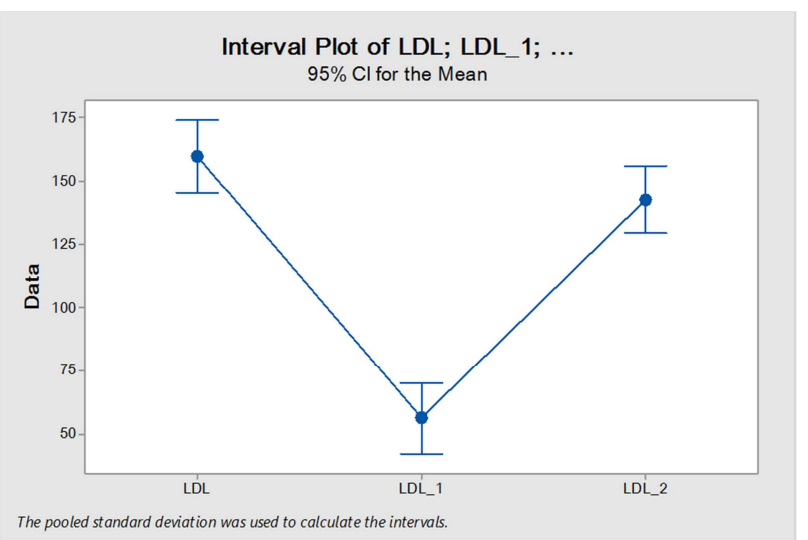

Figure 9. Interval plot analysis to compare between LDL levels for different groups of Vitamin D, LDL_1 (group I; sufficient control group, $n=43$ ), LDL_2 (group II; insufficient vitamin D group, $n=38$ ), LDL (group III; deficient vitamin D group, $n=46$ ). 
Low density lipoprotein (LDL) levels in vitamin D deficient group, normal vitamin D group, and in vitamin D insufficient group was $159.83 \pm 62.81,95 \%$ CI (145.60; $174.06), 56.02 \pm 10.19,95 \%$ CI ( $42.29 ; 69.74)$, and 142.81 \pm 47.69 , 95\% CI (129.54; 156.08), respectively, Figure 9.

\subsection{Testing of Hypothesis}

A complete testing of hypothesis was conducted to check the effect of different levels of concentration of vitamin $\mathrm{D}$ on every lipid parameter concentration.

The testing of hypothesis was conducted on the mean of every parameter compared to other for different levels of vitamin $\mathrm{D}$. The level of significant used in these tests was 0.05 , and if the $p$-value $<0.05$, then the null hypothesis will be rejected. Rejecting the null hypothesis means that the two means are different, otherwise the means are almost equal. The estimated difference in glucose (Glu) in normal vitamin D concentration (group I), insufficient (group II), and deficient (group III) is 129.5 with $95 \%$ CI $(95.6 ; 163.4) \mathrm{P}=0$, 6.5 with $95 \%$ CI $(-34.3$; 47.2) $\mathrm{P}=0.753$, and -123 with $95 \% \mathrm{CI}$ $(-147.0 ;-99.1) \mathrm{P}=0$, respectively. Accordinly null hypothesis $\left(\mathrm{H}_{0}\right)$ is rejected, fail to reject, and rejected in group I, group II, and group III, respectively, Table 3. The estimated difference in total cholesterol in normal vitamin D concentration (group I), insufficient (group II), and deficient (group III) is 114 with $95 \% \mathrm{CI}(91.7 ; 136.6) \mathrm{P}=0,22.5$ with
95\%CI $(-6.4 ; 51.5) \mathrm{P}=0.125$, and -91.6 with $95 \% \mathrm{CI}(-111.56$; -71.65) $\mathrm{P}=0$, respectively. Accordinly null hypothesis $\left(\mathrm{H}_{0}\right)$ is rejected, fail to reject, and rejected in group I, group II, and group III, respectively, Table 3 . The estimated difference in triglycerides (TG) in normal vitamin D concentration (group I), insufficient (group II), and deficient (group III) is 132.6 with $95 \%$ CI $(88.3$; 177.0) $\mathrm{P}=0$, 30.2with 95\%CI (-31.1; 91.4) $\mathrm{P}=0.33$, and -102.5 with $95 \% \mathrm{CI}(-147.2 ;-57.7) \mathrm{P}=0$, respectively. Accordinly the null hypothesis $\left(\mathrm{H}_{0}\right)$ is rejected, fail to reject, and rejected in group I, group II, and group III, respectively, Table 3. The estimated difference in high density lipoprotein (HDL) in normal vitamin D concentration (group I), insufficient (group II), and deficient (group III) is -16.2 with $95 \%$ CI $(-22.32 ;-10.08) \mathrm{P}=0,-1.47$ with $95 \%$ CI ($8.69 ; 5.75) \mathrm{P}=0.69$, and 14.73 with $95 \% \mathrm{CI}(8.01 ; 21.45) \mathrm{P}=0$, respectively. Accordinly null hypothesis $\left(\mathrm{H}_{0}\right)$ is rejected, fail to reject, and rejected in group I, group II, and group III, respectively, Table 3 . The estimated difference in low density lipoprotein (LDL) in normal vitamin D concentration (group I) , insufficient (group II), and deficient (group III) is 103.8with $95 \%$ CI $(83.5$; 124.1) $\mathrm{P}=0,17.0$ with $95 \% \mathrm{CI}(-7.2$; 41.3) $\mathrm{P}=0.166$, and 86.8 with $95 \%$ CI $(72.32$; 101.26) $\mathrm{P}=0$, respectively. Accordinly null hypothesis $\left(\mathrm{H}_{0}\right)$ is rejected, fail to reject, and rejected in group I, group II, and group III, respectively.

Table 3. A complete testing of hypothesis to check the effect of different levels of concentration of vitamin D on every lipid parameter concentration.

\begin{tabular}{|c|c|c|c|c|c|}
\hline No. & Null Hypothesis & Estimated diff. & 95\% C.I. & P-Value & Decision \\
\hline 1 & $M($ Glu. $)-\mu($ Glu. 1$)=0$ & 129.5 & $(95.6 ; 163.4)$ & 0.000 & Reject $\mathrm{H}_{0}$ \\
\hline 2 & $\mu$ (Glu.) $-\mu$ (Glu._2) $=0$ & 6.5 & $(-34.3 ; 47.2)$ & 0.753 & Fail to Reject $\mathrm{H}_{0}$ \\
\hline 3 & $\mu($ Glu._1) $-\mu$ (Glu. 2$)=0$ & -123 & $(-147.0 ;-99.1)$ & 0 & Reject $\mathrm{H}_{0}$ \\
\hline 4 & $\mu$ (T. Chol. $)-\mu$ (T. Chol._1) $=0$ & 114 & $(91.7 ; 136.6)$ & 0 & Reject $\mathrm{H}_{0}$ \\
\hline 5 & $\mu$ (T. Chol. $)-\mu$ (T. Chol. 2$)=0$ & 22.5 & $(-6.4 ; 51.5)$ & 0.125 & Fail to Reject $\mathrm{H}_{0}$ \\
\hline 6 & $\mu($ T. Chol._1) $-\mu$ (T. Chol. 2$)=0$ & -91.6 & $(-111.56 ;-71.65)$ & 0 & Reject $\mathrm{H}_{0}$ \\
\hline 7 & $\mu(\mathrm{TG})-\mu\left(\mathrm{TG} \_1\right)=0$ & 132.6 & $(88.3 ; 177.0)$ & 0 & Reject $\mathrm{H}_{0}$ \\
\hline 9 & $\mu($ TG_1 $)-\mu($ TG_2 $)=0$ & -102.5 & $(-147.2 ;-57.7)$ & 0 & Reject $\mathrm{H}_{0}$ \\
\hline 10 & $\mu(\mathrm{HDL})-\mu\left(\mathrm{HDL}_{-} 1\right)=0$ & -16.2 & $(-22.32 ;-10.08)$ & 0 & Reject $\mathrm{H}_{0}$ \\
\hline 11 & $\mu(\mathrm{HDL})-\mu\left(\mathrm{HDL}_{2} 2\right)=0$ & -1.47 & $(-8.69 ; 5.75)$ & 0.687 & Fail to Reject $\mathrm{H}_{0}$ \\
\hline 12 & $\mu\left(\mathrm{HDL}_{-} 1\right)-\mu\left(\mathrm{HDL} \_2\right)=0$ & 14.73 & $(8.01 ; 21.45)$ & 0 & Reject $\mathrm{H}_{0}$ \\
\hline 13 & $\mu(\mathrm{LDL})-\mu\left(\mathrm{LDL}_{-} 1\right)=0$ & 103.8 & $(83.5 ; 124.1)$ & 0 & Reject $\mathrm{H}_{0}$ \\
\hline 14 & $\mu(\mathrm{LDL})-\mu\left(\mathrm{LDL}_{-} 2\right)=0$ & 17.0 & $(-7.2 ; 41.3)$ & 0.166 & Fail to Reject $\mathrm{H}_{0}$ \\
\hline 15 & $\mu\left(\mathrm{LDL} \_2\right)-\mu\left(\mathrm{LDL} \_1\right)=0$ & 86.8 & $(72.32 ; 101.26)$ & 0.000 & Reject $\mathrm{H}_{0}$ \\
\hline
\end{tabular}

\section{Discussion}

Our study demonsrated that $66 \%$ of the subjects are vitamin D insufficient and deficient. This finding is conformed with previous reports [14, 15]. Vitamin D deficiency could be due to different reasons such as; feeding much fiber rich food that affect vitamin D absorbtion, restricted intake of fish and fish oil which is rich in vitamin D, limited exposure to sunlight due to different reasons, having dark skin with melanin that reduces the ability of the skin to synthesize vitamin $\mathrm{D}$, problems in digestive tract due to some diseases that interfer with vitamin $\mathrm{D}$ absorption, or due to obesity in which fat cells extract vitamin D from blood.
This study showes a significant increase in the mean total cholesterol, triglycerides, and LDL, and a significant decrease in HDL levels with deficiency and insufficiency of vitamine D compared with normal sufficient vitamin D subjects. Cholesterol level is increased significantly with deficiency and with insufficiency of vitamin D. This finding is in agreement with many reported studied [16-19]. This finding of hypercholesterolemia with hypovitamin $\mathrm{D}$ is explained if there was a defect in LDL receptors and thus a defect in cholesterol uptake, so cholesterol level in blood will be increased and vitaminD will be decreased because both of them has a common synthetic pathway and it is reported that LDL cholesterol is a precursr of previtamin D [20-24].

In this study Hypertriglyceridemia was demonstrated with 
low serum level of vitamin D in patients with vitamin D deficiency and insufficiency which coincide with other studies $[25,26]$. It is reported that vitamin D reduces serum level of triglycerides by increasing serum calcium via intestinal absorption. This calcium reduces the synthesis of triglycerides in the liver and its secretion [27]. Another mechanism is to reduce triglycerides via PTH suppression [28].

As shown in Table II, low level of HDL is observed with low level of vitamin $\mathrm{D}$ in the deficient and insufficient vitamin D patients. This finding is similar to what other investigators reported [29, 30].

\subsection{Normality Test}

This test compares the empirical cumulative distribution function of the sample data with the distribution expected if the data were normal. If this observed difference is sufficiently large, the test will reject the null hypothesis of population normality.

H0: data follow a normal distribution vs H1: data do not follow a normal distribution. As shown in figures 2, 3, and 4, one could conclude that data from normal lipid/sufficient vitamin $\mathrm{D}$, hyperlipidemic/insufficient vitamin $\mathrm{D}$, and hyperlipidemic/deficient vitamin D groups, all follow the normal distribution due to the fact that $\mathrm{P}$-value is greater than 0.05 . Therefore we fail to reject the null hypothesis.

\subsection{Comparison Between Lipid Parameters for Different Groups of Vitamin D and Analysis of Variances}

Our data show that the mean level of the glucose (figure 5), cholesterol (figure 6), triglycerides (figure 7), and LDL (figure 9), for the control group of sufficient vitamin D /nomolipids is lower than the insufficient vitamin $\mathrm{D} /$ hyperlipidmic and deficient vitamin $\mathrm{D} /$ hyperlipidimic groups. It is concluded that insufficiency of vitamin D or deficiency has a significant effect on the glucose, cholesterol, triglycerides, and LDL levels and it will increase them to more than the double. For HDL, it is noted from (figure 8) that the mean of the HDL for sufficient vitamin D /nomolipids group is higher than insufficient vitamin D/hyperlipidimic and deficient vitamin D/hyperlipidimic groups. This means that the effect of Vitamin D insufficiency or deficiency has a significant effect on the HDL level and it will decrease it to almost $30 \%$.

\subsection{Testing of Hypothesis}

A complete testing of hypothesis was conducted to check the effect of different levels of concentration of vitamin D on every lipid parameter concentration (TableIII). The testing of hypothesis was conducted on the mean of every parameter compared to other for different levels of vitamin $\mathrm{D}$. The level of significant used in these tests was 0.05 , and if the p-value $<0.05$, then the null hypothesis will be rejected. Rejecting the null hypothesis means that the two means are different, otherwise the means are almost equal. It is concluded from Table III that there are differences between the levels of lipid parameters in normal vitamin D concentration (control), insufficient vitamin D patients, and deficient vitamin D group. On the other hand, it is noted that there is no differences between the lipid parameters in the insufficient and deficient vitamin D .

\section{Conclusion}

Vitamin D deficiency and insufficiency have high frequency in the tested sample in eastren province of Amman, Jordan. Dyslipidemia could be a result of vitamin D deficiency and insufficiency. A significant effect of vitamin D insufficiency or deficiency on serum level of cholesterol, triglycerides, and LDL and increases the levels more than the double and decreases the level of HDL. No difference between the lipid profile parameters in the deficient and insufficient vitamin D . In order to understand the relationship between vitamin D and serum lipid profiles, large randomized, controlled studies are required

Ethical approval: "All procedures performed in studies involving human participants were in accordance with the ethical standards of Jordan university of science and technology research committee and with the 1964 Helsinki declaration and its later amendments or comparable ethical standards."

\section{Acknowledgements}

The study was supported by Jordan university of science and technology deanship of scientific research.

\section{References}

[1] Richa Giri, Rohit Rai, Rajendra Kumar Verma, Shivendra Verma . Correlation between vitamin D and lipid profile in patients with ischemic stroke DOI: http://dx.doi.org/10.18203/2320-6012.ijrms, 2016.1805.

[2] Pallavi M, Amarjeet S B: Diminished Levels of Vitamin D and Altered Lipid Profile DOI: https://dx.doi.org/10.18535/jmscr/v5i6.148

[3] Zaher F, Sumay H, Muhammad B H, Safa , and Abdul A. Vitamin D deficiency plays an important role in cardiac disease and affects patient outcome: Still a myth or a fact that needs exploration? J Saudi Heart Assoc. 2015 Oct; 27(4): 264-271. Published online 2015 Feb 14. doi: 10.1016/j.jsha.2015.02.003. PMCID: PMC4614899, PMID: 26557744

[4] Liyanage GC1, Lekamwasam S2, Weerarathna TP2, Liyanage CE3Diabetes Metab Syndr. 2017 Dec; 11 Suppl 2: S767-S770. doi: 10.1016/j.dsx.2017.05.013. Epub 2017 Jun 3. Effects of high-dose parenteral vitamin D therapy on lipid profile and blood pressure in patients with diabetic nephropathy: A randomized double-blind clinical trial.

[5] Kunutsor SK, Apekey TA, Steur M. Vitamin D and risk of future hypertension: meta-analysis of 283,537 participants. Eur J Epidemiol. 2013; 28(3): 205-221. doi: 10.1007/s10654013-9790-2. [PubMed] [Cross Ref] 
[6] Daniel Mauss1 , Marc N. Jarczok1, Kristina Hoffmann1, G. Neil Thomas1,2, Joachim E. Fischer1. Association of Vitamin D Levels with Type 2 Diabetes in Older Working Adults, International Journal of Medical Sciences, 2015; 12(5): 362368. doi: 10.7150/ijms.10540.

[7] Afzal S, Bojesen SE, Nordestgaard BG. Low 25hydroxyvitamin $\mathrm{D}$ and risk of type 2 diabetes: a prospective cohort study and metaanalysis. Clin Chem. 2013; 59(2): 381391. doi: 10.1373/clinchem.2012.193003. [PubMed] [Cross Ref]

[8] Forouhi NG, Ye Z, Rickard AP, Khaw KT, Luben R, Langenberg C, Wareham NJ. Circulating 25-hydroxyvitamin $\mathrm{D}$ concentration and the risk of type 2 diabetes: results from the European Prospective Investigation into Cancer (EPIC)Norfolk cohort and updated meta-analysis of prospective studies. Diabetologia. 2012; 55(8): 2173-2182. doi: 10.1007/s00125-012-2544-y. [PubMed] [Cross Ref]

[9] Jorde R, Grimnes G. Vitamin D and metabolic health with special reference to the effect of vitamin D on serum lipids. Prog Lipid Res. 2011; 50(4): 303-312. doi: 10.1016/j.plipres.2011.05.001. [PubMed] [Cross Ref]

[10] Paul L, Marelise E , Natasjavan S, Mirjam O , Renatede J, Yvonne KP, and Suat S. Vitamin D and type 2 diabetes, The Journal of Steroid Biochemistry and Molecular Biology, Volume 173, October 2017, Pages 280-285

[11] Jafari T, Faghihimani E, Feizi A, Iraj B, Javanmard SH, Esmaillzadeh A, Fallah AA, Askari G. Clin Nutr. 2016 Feb; 35(1): 67-76. doi: 10.1016/j.clnu.2015.02.014. Epub 2015 Mar 5. Effects of vitamin D-fortified low fat yogurt on glycemic status, anthropometric indexes, inflammation, and bone turnover in diabetic postmenopausal women: A randomised controlled clinical trial.

[12] Skaaby $\mathrm{T}$, Thuesen BH, Linneberg A. Vitamin D, Cardiovascular Disease and Risk Factors. Adv Exp Med Biol. 2017; 996: 221-230. doi: 10.1007/978-3-319-56017-5_18.

[13] Raposo L, Martins S, Ferreira D, Guimarães JT, Santos AC. Vitamin D, parathyroid hormone and metabolic syndrome . BMC Endocr Disord. 2017 Nov 17; 17(1): 71. doi: 10.1186/s12902-017-0221-3.

[14] Jafari T, Fallah AA, Barani A. Effects of vitamin D on serum lipid profile in patients with type 2 diabetes: A meta-analysis of randomized controlled trials Clin Nutr. 2016 Dec; 35(6): 12591268. doi: 0.1016/j.clnu.2016.03.001. Epub 2016 Mar 15.

[15] Tamer G; Telci C O; Gungor K; Kartal I; Sagun HG,; Arik S, Bozkurt CI; MutluHH. Effect of vitamin D status on lipid profile in premenopausal women: a cross-sectional study. Cardiovascular Endocrinology \& Metabolism: June 2017. Volume 6 - Issue 2 - $\mathrm{p}$ 86-91, doi: 10.1097/XCE.0000000000000124, DOI: http://dx.doi.org/10.18203/2320-6012.ijrms20161805

[16] Monlezun D J., Camargo CA., Mullen JT. , Quraishi SA. Vitamin D Status and the Risk of Anemia in CommunityDwelling Adults: Results from the National Health and Nutrition Examination Survey 2001-2006, Medicine: December 2015 - Volume 94 - Issue 50 - p e1799, doi: 10.1097/MD.0000000000001799

[17] Karhapää J. Pihlajamäki I. Pörsti G“'Diverse associations of 25hydroxyvitamin $\mathrm{D}$ and 1,25-dihydroxy-vitamin $\mathrm{D}$ with dyslipidaemias," Journal of Internal Medicine, vol. 268, no. 6, pp. 604-610, 2010. View at Publisher - View at Google
Scholar $\cdot$ View at Scopus.

[18] Verena Schwetz, , Hubert Scharnagl, Tatjana Stojakovic, Marlene Pandis, Martin R. Grübler, Nicolas Verheyen, Martin Gaksch, Armin Zittermann, Felix Aberer, Elisabeth Lerchbaum, Barbara Obermayer-Pietsch, Thomas R. Pieber, Winfried März, Andreas Tomaschitz, Stefan Pilz. Vitamin D supplementation and lipoprotein metabolism: A randomized controlled trial. Journal of clinical lipdology, May-June, 2018Volume 12, Issue 3, Pages 588-596.e4, DOI: https://doi.org/10.1016/j.jacl.2018.03.079.

[19] Alkippi N, Marina T, Nikolaos M, Anargyros M, Anastassios P, and Michael K. Vitamin D in cardiovascular disease, doi: 10.21873/invivo.11338, In Vivo September-October 2018 vol. 32 no. 5 977-981.

[20] Choi h s., Kim K. A., Lim C. Y. "Low serum vitamin D is associated with high risk of diabetes in Korean adults," Journal of Nutrition, vol. 141, no. 8, pp. 1524-1528, 2011. View at Publisher · View at Google Scholar · View at Scopu

[21] Gagnon C, Lu ZX, Magliano DJ, Dunstan DW, Shaw JE, Zimmet PZ, Sikaris K, Ebeling PR, Daly RM. Low serum 25hydroxyvitamin $\mathrm{D}$ is associated with increased risk of the development of the metabolic syndrome at five years: results from a national, population-based prospective study (The Australian Diabetes, Obesity and Lifestyle Study: AusDiab). J Clin Endocrinol Metab 2012; 97: 1953 - 61; http://dx.doi.org/10.1210/jc.2011-3187; PMID: 22442263.

[22] García-Bailo B, Da Costa LA, Arora P, Karmali M, El-Sohemy A, Badawi A. Plasma vitamin D and biomarkers of cardiometabolic disease risk in adult Canadians, 2007-2009. Prev Chronic Dis 2013; 10: E91; http://dx.doi.org/10.5888/pcd10.120230; PMID: 23742939

[23] Anania LC, Osborn JF, Ferraro F, Bonci E, Olivero E, Chiesa C. Low 25(OH)D3 levels are associated with total adiposity, metabolic syndrome, and hypertension in Caucasian children and adolescents. Eur J Endocrinol 2011; 165: 603 - 11; http://dx.doi.org/10.1530/EJE-11-0545; PMID: 21753070.

[24] Mohammed S D, Association between Vitamin D deficiency and psoriasis: An exploratory study, Int J Health Sci (Qassim). 2018 Jan-Feb; 12(1): 33-09. PMCID: PMC5870311, PMID: 29623015 .

[25] Hajas A, Sandor J, Csathy L, Csipo I, Barath S, Paragh G, Seres I, Szegedi G, Shoenfeld Y, Bodolay E. Vitamin D insufficiency in a large MCTD population. Autoimmun Rev 2011; 10: 317 24; http://dx.doi.org/10.1016/j.autrev.2010.11.006; PMID: 21156217

[26] Cigolini M., Iagulli MP, Miconi V., Galiotto M., Lombardi S., and Targher G., "Serum 25-hydroxyvitamin D3 concentrations and prevalence of cardiovascular disease among type 2 diabetic patients," Diabetes Care, vol. 29, no. 3, pp. 722-724, 2006. View at Google Scholar · View at Scopus.

[27] Asma MA, and Naser AA, Current Evidence on Vitamin D Deficiency and Metabolic Syndrome in Obese Children: What Does the Evidence from Saudi Arabia Tell Us? Children (Basel) 2018 Jan; 5(1): 11. Published online 2018 Jan 15. doi: 10.3390/children5010011, PMCID: PMC5789293, PMID: 29342981

[28] Choi HS., Kim KA., Lim CY. "Low serum vitamin D is associated with high risk of diabetes in Korean adults," Journal of Nutrition, vol. 141, no. 8, pp. 1524-1528, 2011. View at Publisher · View at Google Scholar · View at Scopus. 
[29] Ahmadi F, Mirjafari SR, Khatami MR, Khazaeipour Z, Ranjbarnovin N. Relationship between serum parathyroid hormone levels and lipid profile in non-diabetic hemodialysis patients. Saudi J Kidney Dis Transpl 2012; 23: 1188-95.
[30] Antonio JL, Jamerson RC, Maria LGR, Diego BCB. Vitamin D Deficiency and Cardiovascular Diseases, Int. J. Cardiovasc. Sci. vol.31 no.4 Rio de Janeiro July/Aug. 2018 Epub May 21, 2018, http://dx.doi.org/10.5935/2359-4802.20180025. 